Viso - Cadernos de estética aplicada

Revista eletrônica de estética

ISSN 1981-4062

$N^{\circ} 16$, jan-jun/2015

http://www.revistaviso.com.br/

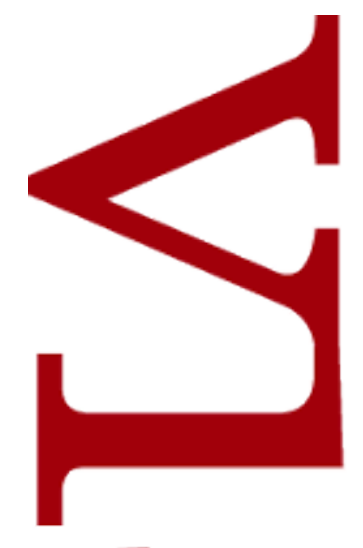

\title{
Eduardo Coimbra: Arquitetura, escultura e desastre Otavio Leonidio
}

Pontifícia Universidade Católica do Rio de Janeiro (PUC-Rio)

Rio de Janeiro, Brasil 


\section{RESUMO}

Eduardo Coimbra: Arquitetura, escultura e desastre

O artigo trata da obra recente do artista plástico Eduardo Coimbra, de viés francamente arquitetônico. Para tanto, lança mão do aparato teórico formulado pelo arquiteto e teórico norte-americano Peter Eisenman, em especial suas formulações acerca do que chama de "metafísica da presença".

Palavras-chave: Eduardo Coimbra - arte contemporânea - Peter Eisenman experiência - metafísica da presença

\section{ABSTRACT}

\section{Eduardo Coimbra: Architecture, Sculpture and Disaster}

The essay addresses the recent work of the Brazilian artist Eduardo Coimbra, with an emphasis on its architectural inclination. In order to do so, the author resorts to the theoretical oeuvre of Peter Eisenman, in particular his ideas about what he has named the metaphysics of the architectural presence.

Keywords: Eduardo Coimbra - contemporary art - Peter Eisenman - experience metaphysics of presence 
LEONIDIO, O. "Eduardo Coimbra: Arquitetura, escultura e desastre". In: Viso: Cadernos de estética aplicada, v. IX, n. 16 (jan-abr/2015), pp. 27-44.

DOI: 10.22409/1981-4062/v16i/194

Aprovado: 23.05.2015. Publicado: 30.07.2015.

(C) 2015 Otavio Leonidio. Esse documento é distribuído nos termos da licença Creative Commons Atribuição-NãoComercial 4.0 Internacional (CC-BY-NC), que permite, exceto para fins comerciais, copiar e redistribuir o material em qualquer formato ou meio, bem como remixá-lo, transformá-lo ou criar a partir dele, desde que seja dado o devido crédito e indicada a licença sob a qual ele foi originalmente publicado.

Licença: http://creativecommons.org/licenses/by-nc/4.0/deed.pt_BR

Accepted: 23.05.2015. Published: 30.07.2015.

(C) 2015 Otavio Leonidio. This document is distributed under the terms of a Creative Commons Attribution-NonCommercial 4.0 International license (CC-BY-NC) which allows, except for commercial purposes, to copy and redistribute the material in any medium or format and to remix, transform, and build upon the material, provided the original work is properly cited and states its license.

License: http://creativecommons.org/licenses/by-nc/4.0/ 
There is an attempt to diminish the distinctions between architecture and sculpture as architects overlap the nonfunctional determination of sculpture into their constructs. The converse is not the problem of my sculpture Richard Serra, "Interview”, $1975^{1}$

Fatos arquitetônicos integra o movimento mais recente da obra de Eduardo Coimbra. É o mais difícil também.

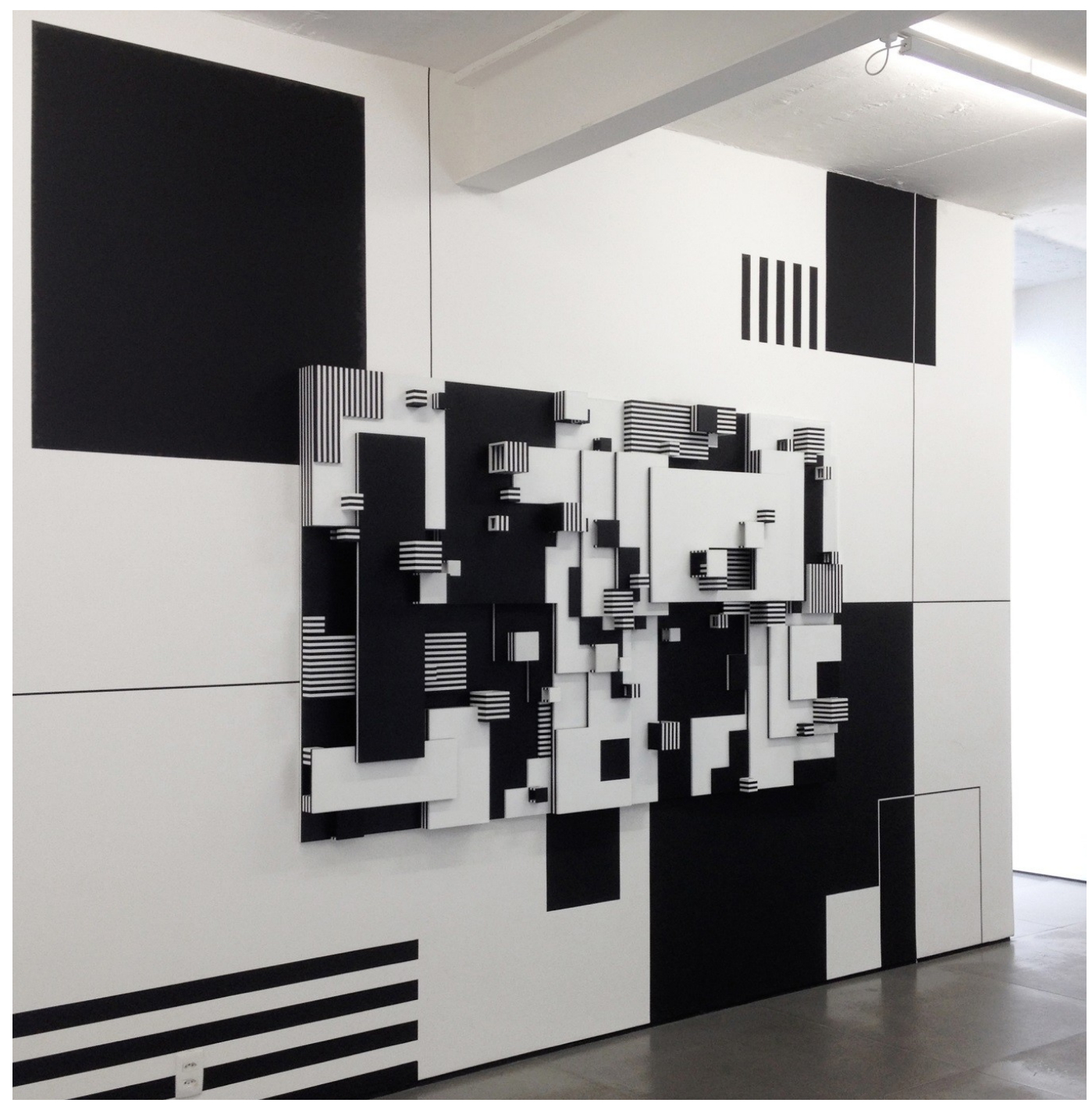

Fato arquitetônico. Eduardo Coimbra, Galeria Nara Roesler, Rio de Janeiro, 2015

Que a arquitetura, em suas diversas dimensões e instâncias (a urbana inclusive), foi sempre um tema central da pesquisa de Coimbra, é evidente. Faz de fato bastante tempo que o artista investiga, e sobretudo afronta, algumas das noções e categorias mais elementares do discurso arquitetônico. A noção de "paisagem" (não exclusiva, mas todavia central à arquitetura), abordada à exaustão pela obra de Coimbra, é talvez a ocorrência mais óbvia no quadro de uma prática que, não raro, opera no limite entre arquitetura e tudo aquilo que o discurso da arquitetura, por costume ou precaução, não 
se dispõe a incorporar.

O rendimento dessas incursões pelo território discursivo da arquitetura foi sempre muito alto. Delas resultaram algumas das coisas mais instigantes já produzidas pelo artista. Seus Horizontes e Paisagens, por exemplo, são bem mais do que coisas estranhas e desconcertantes. São coisas que nos facultam estranhar o modo convencional e por regra irrefletido como lidamos com as representações mais familiares do espaço "real", natural ou construído. Dito de outro modo, o que essas coisas possibilitam é colocar em questão as noções vigentes de espaço - noções sem as quais o mundo "real" deixa de parecer familiar e acolhedor, e se transforma em inóspito e impraticável.

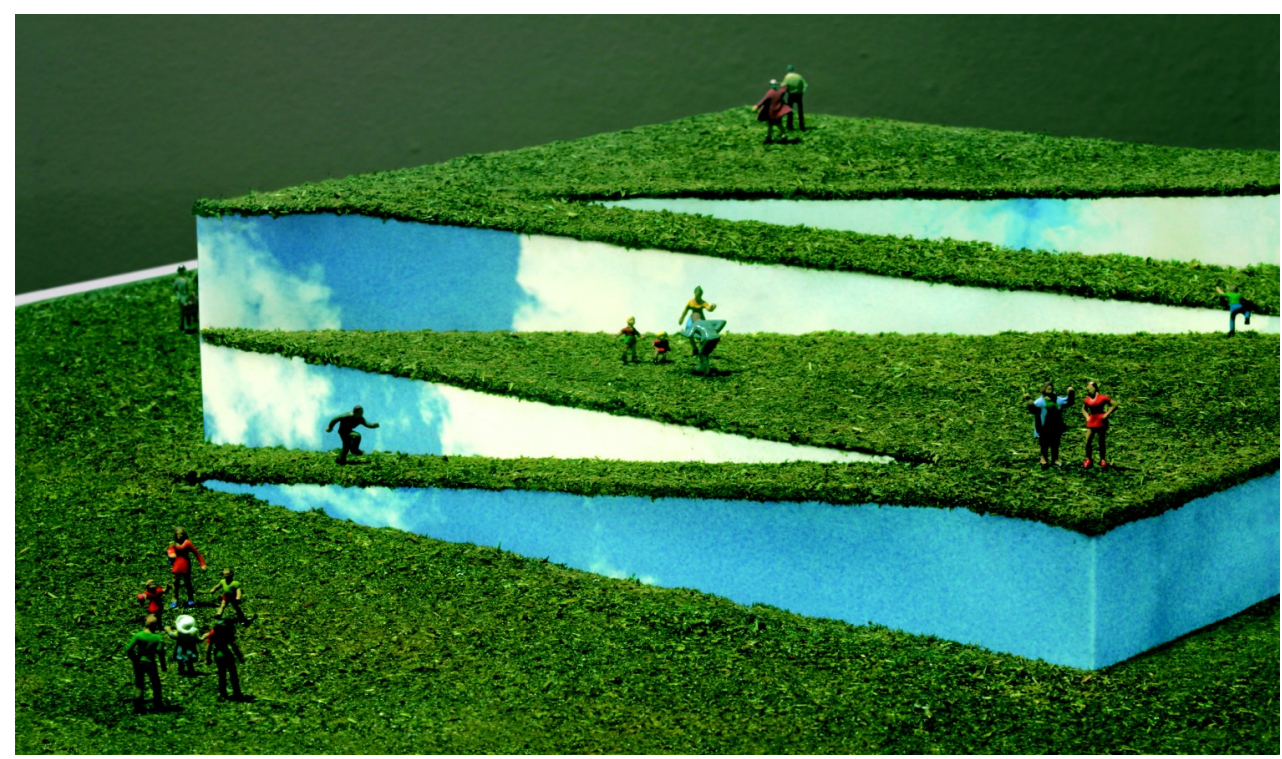

Horizontes III.Eduardo Coimbra, 2001

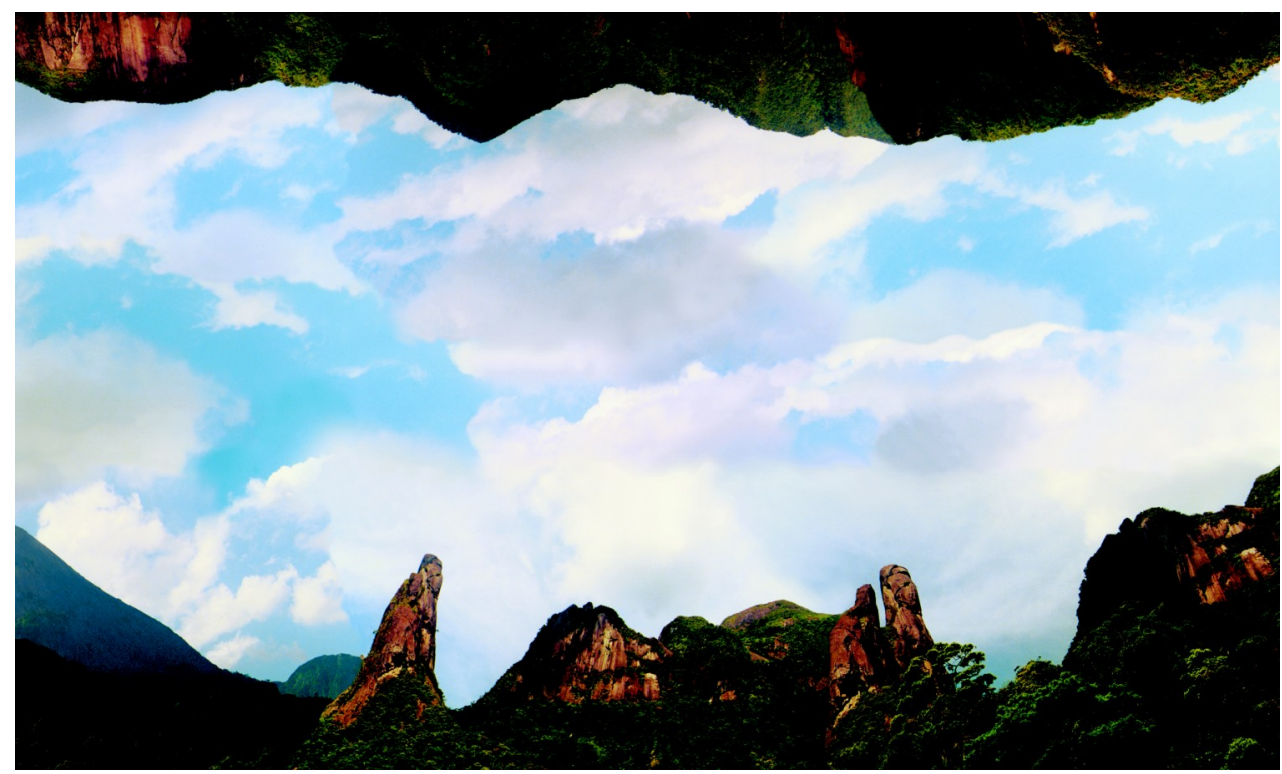

Paisagem. Eduardo Coimbra, 2000 
A série Estádios demonstra, de resto, que as incursões de Coimbra pelo território da arquitetura não se limitaram à desconstrução de noções e categorias elementares do discurso da arquitetura; incluíram também a desestabilização de um dos dispositivos mais caros à projetação arquitetônica: a maquete. Neste caso, também, a operação de Eduardo Coimbra se revelou altamente produtiva. Pois quem vê aquelas inusitadas maquetes não divisa apenas a possibilidade de práticas esportivas insólitas; dá-se conta do caráter essencialmente problemático de um dos dispositivos mais consagrados da práxis arquitetônica, fundado no princípio da correspondência mais ou menos lógica e natural entre uma representação metonímica do real (a maquete) e o real ele mesmo (o edifício).

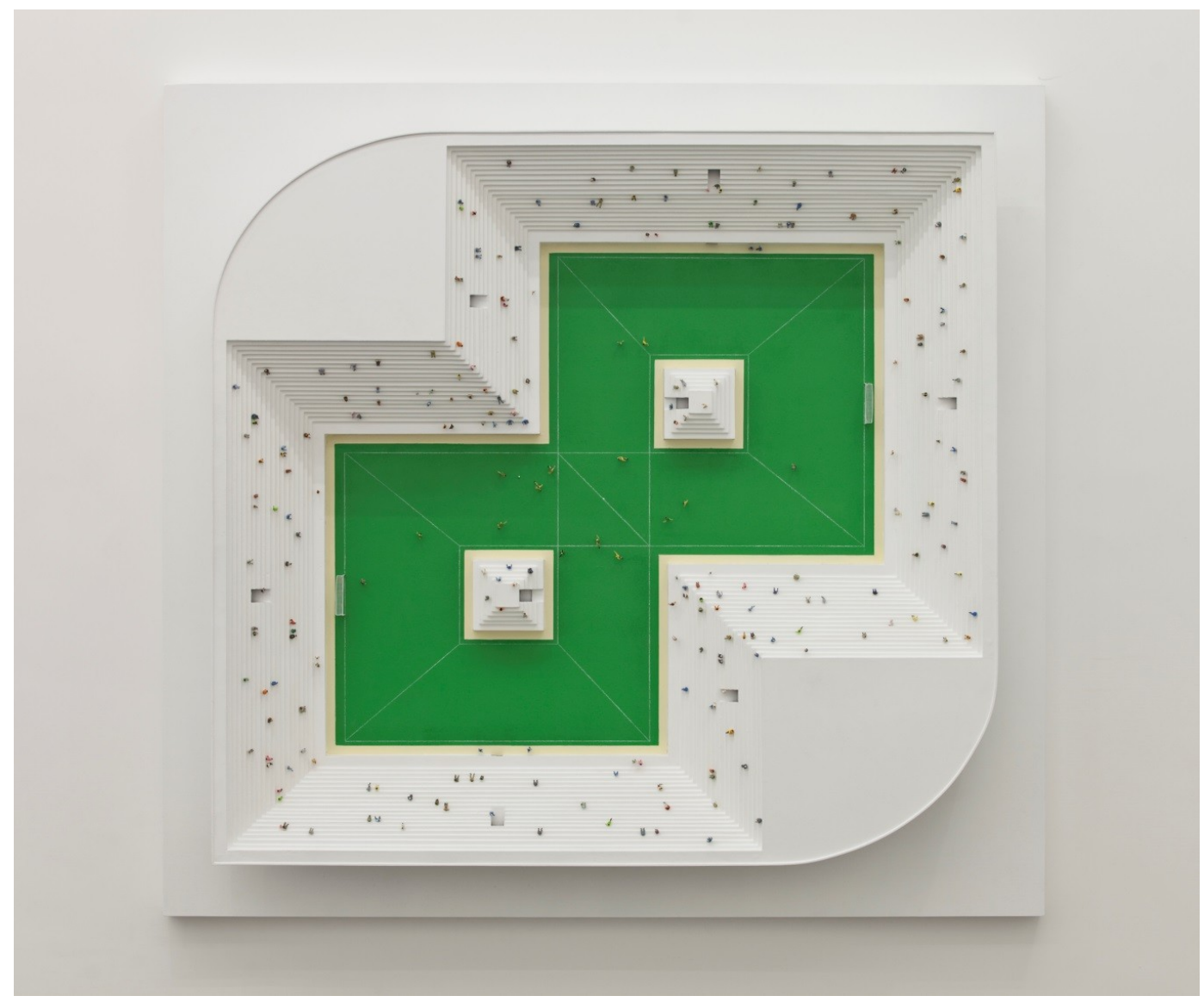

Estádio III. Eduardo Coimbra, 2011

Ao quebrar, por força do estranhamento, essa conexão mais ou menos imediata, e supostamente lógica, entre real e representação do real, Coimbra não põe em xeque apenas a operacionalidade de um dispositivo tradicional de representação do real (se se quiser, do real da arquitetura); ele expõe o grau de dependência entre uma ideia de real e os dispositivos (no caso, analógicos - desenhos, gráficos, diagramas, etc) vigentes de representação do real, por regra naturalizados.

Para além disso, abre-se a possibilidade de perceber, não raro de modo vertiginoso (a 
vertigem é, afinal, um dos traços característicos das poéticas do artista) o grau de interdependência entre aquilo que costumamos chamar (no Brasil pós-Neoconcreto, meio automaticamente) de "experiência" do real e modelos preconcebidos de espaço no caso, um modelo que, entre outras coisas, pressupõe uma distinção categórica e hierárquica entre, de um lado, representações (gráficas, volumétricas, mas também mentais) do edifício e, de outro, a experiência fenomenológica do edifício ele mesmo. Significativamente, os Estádios de Eduardo Coimbra ensejam um tipo de relação com a maquete que extrapola aquele subjacente ao discurso das representações arquitetônicas, segundo o qual a experiência propriamente dita do espaço arquitetônico deve ficar sempre restrita ao âmbito do edifício ele mesmo, e não às suas representações gráficas, volumétricas etc. O que todas essas operações acusam, fica claro, é isto: o regime de representação icônico (baseado no princípio da semelhança autoevidente entre signo e referente) não é menos arbitrário e em certo sentido metafísico do que o regime simbólico (aquele que lança mão de signos codificados).

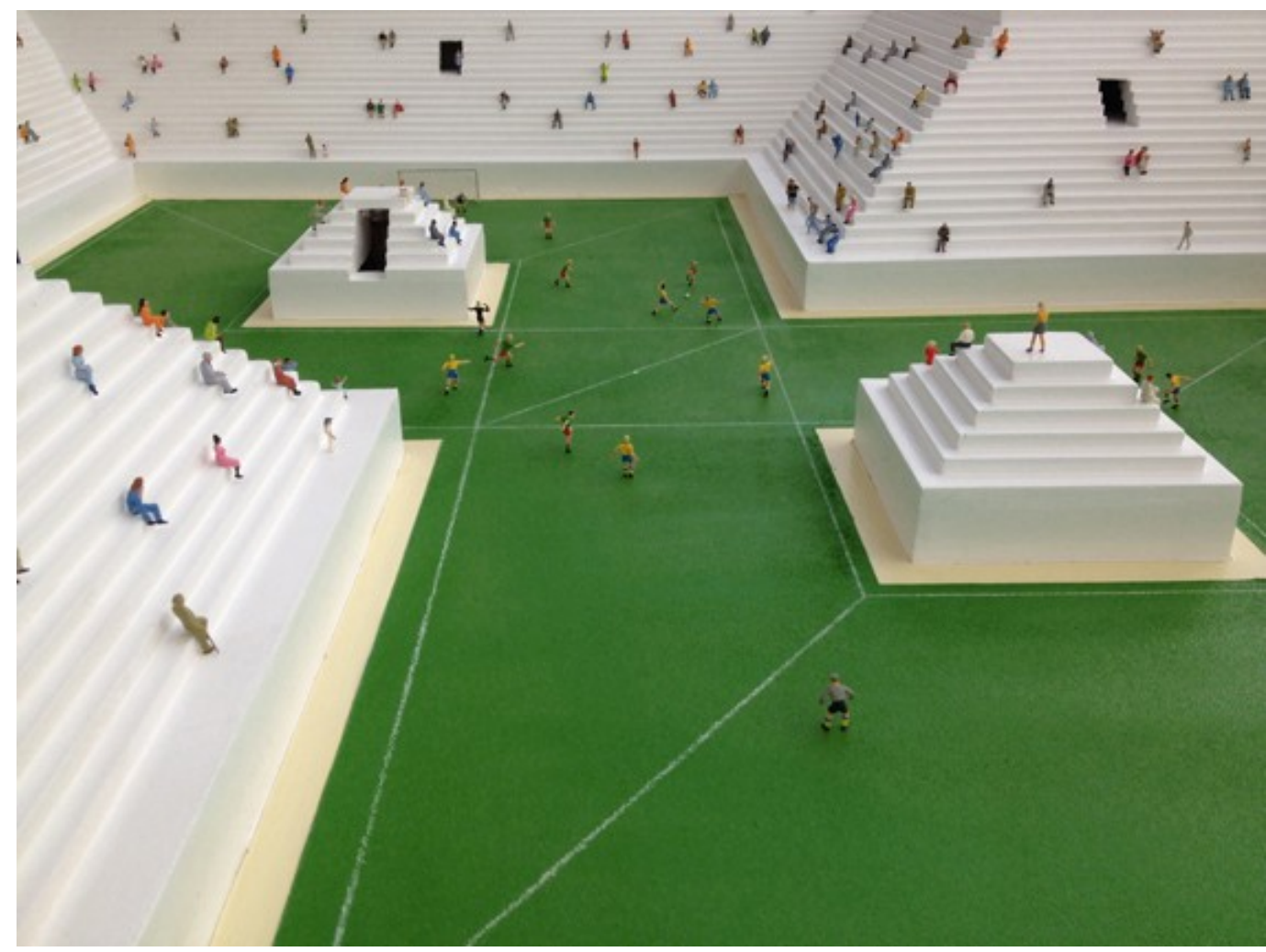

Estádio III. Eduardo Coimbra, 2011

Cabe destacar ainda outro aspecto essencial de todas as operações arquitetônicas de Coimbra - a saber, o fato de que tudo ou quase tudo que ali se representava sempre se quis explicitamente absurdo: céu embutido no pórtico de concreto (Welcome to Rio, 2001), céu embaixo de chão (Passos silenciosos, 1994), chão que flutua sobre o céu (Paisagem, 2000). O que significa dizer que, na prática, a eficácia semiótica (mas também o rendimento estético) de todas essas operações sempre se beneficiou do fato 
de que todos nós sabemos, e desde sempre, que o céu "real" não se localiza sob nossos pés, senão sobre nossas cabeças - e assim por diante. Da parte de quem vê as obras, portanto, nunca houve muita margem para hesitação ou dilema: diante daquelas coisasimagens, a adesão ou era imediata ou simplesmente não era. Não há obviamente nada de censurável em tirar partido da lógica do contrassenso (que o diga Duchamp!). Mas é certo que isso sempre se constituiu numa facilidade (à qual somava-se o caráter desavergonhadamente sedutor das coisas produzidas por Coimbra).

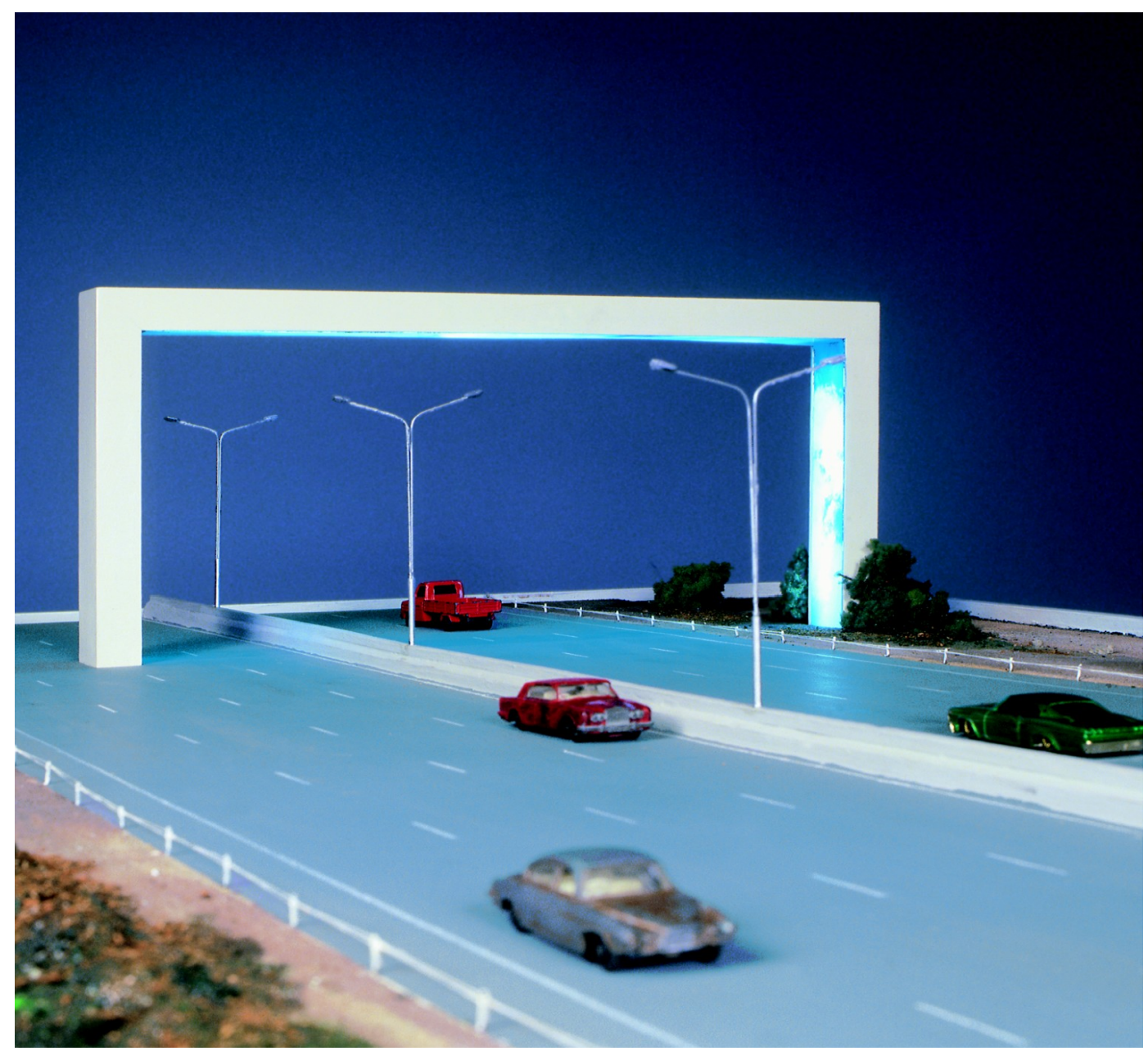

Welcome to Rio. Eduardo Coimbra, 2011 


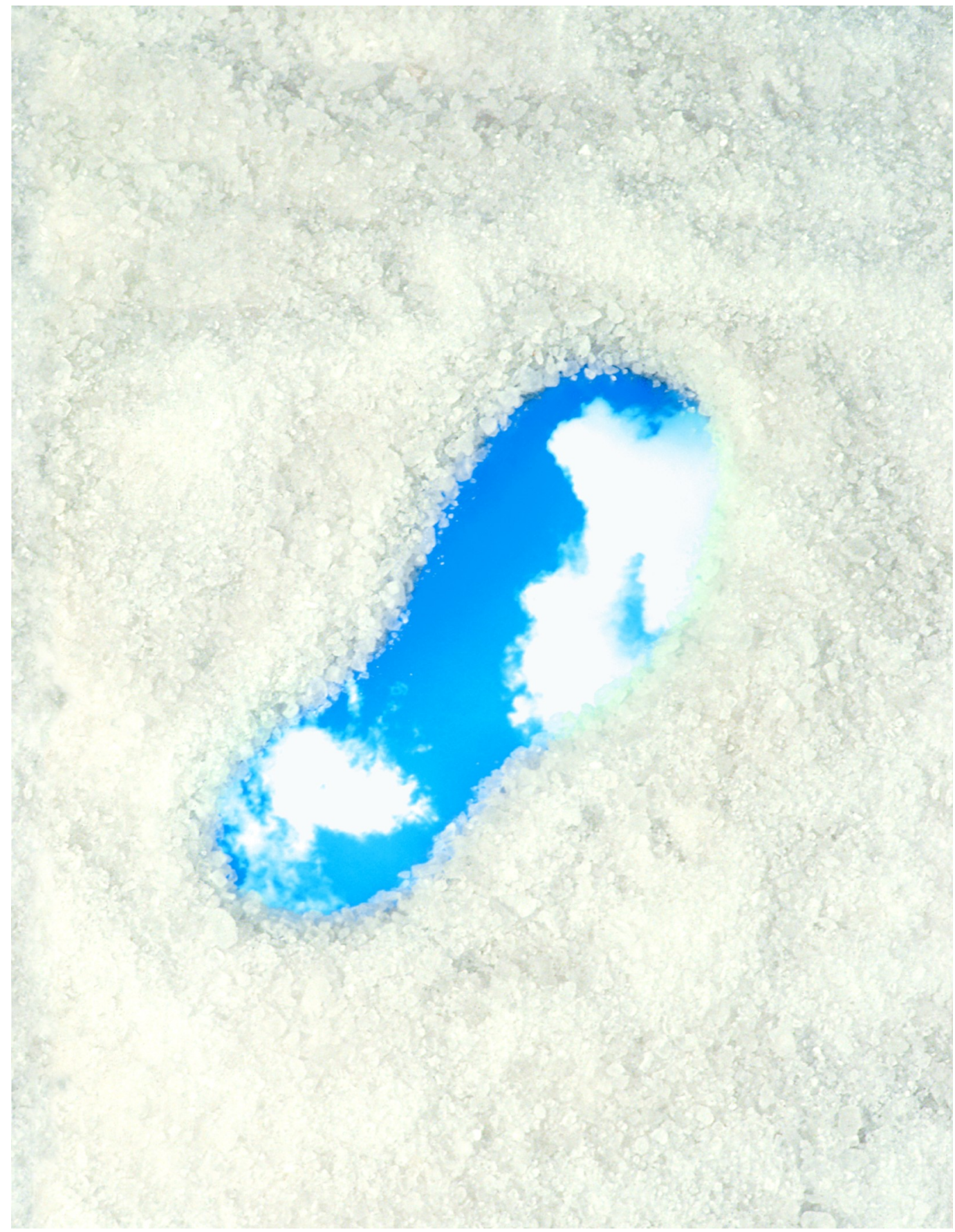

Mais recentemente, contudo, Eduardo Coimbra parece ter feito uma opção por explorar o território discursivo da arquitetura em termos bastante mais complexos - e, como disse de saída, incomparavelmente mais difíceis (para ele e para seu público). Pois, até onde percebo, Coimbra parece decidido a explorar aquilo que o arquiteto e teórico norte americano Peter Eisenman perceptivamente denominou a metafísica da presença arquitetônica. O que a define? Segundo Eisenman, o fato de que, em contraste com outros regimes de representação (o pictórico, por exemplo), a arquitetura vem sempre 
acompanhada de uma insuperável "promessa de realidade". ${ }^{2}$ Mais elaboradamente, a metafísica da presença advém de que, diante de um edifício, não supomos jamais estar diante de uma representação do real construído, senão em contato com o real construído ele mesmo. Noutras palavras, em presença da arquitetura, não supomos jamais estar diante (não prioritariamente, e menos ainda exclusivamente) de um conjunto de signos, senão das coisas elas mesmas - a começar por seus componentes mais elementares: piso, parede, teto, coluna, janela, etc.

E no entanto, afirma Eisenman, é justamente essa pressuposição (supostamente óbvia) aquilo que impede que nos relacionemos com a arquitetura de modo imediato (vale dizer, não mediado por um sistema de signos). Pois, segundo ele, na prática simplesmente não somos capazes de dissociar a "condição substantiva" ${ }^{3}$ dos elementos arquitetônicos (sua mera coisidade) de sua condição icônica (isto é, o fato de que tais elementos representam a função que desempenham no contexto específico da arquitetura).

Eisenman tem razão. Dado que, desde sempre, o que se entende por arquitetura se vincula a uma condição muito particular de construção e abrigo (o que sempre garantiu que ela não se confundisse com todas aquelas coisas que, sendo construção, e eventualmente abrigo, jamais se qualificaram como arquitetura stricto sensu - por exemplo, obeliscos, arcos triunfais, terraplenos, mas também esculturas, as do chamado "campo ampliado"4 sobretudo), na prática não somos capazes de dissociar, por exemplo, o componente coluna da ideia de coluna - ou seja, do fato de que, por definição, uma coluna atua para manter o edifício de pé. Assim é que toda vez que me encontro diante daquela coluna específica, da coluna que jaz ali diante dos meus olhos e ao alcance de minhas mãos, não sou capaz percebê-la em sua mera coisidade; pelo contrário, tendo sempre, atavicamente, a referi-la à sua função estrutural-arquitetônica - à sua "colunidade". ${ }^{5}$ O mesmo vale para os elementos que, no contexto específico da arquitetura, desempenham as funções de piso, parede e teto: ao caminhar sobre as coisas que, no edifício, se encontram sob meus pés, caminho sempre sobre "lajes", "rampas", "escadas" - como se sabe, componentes essenciais dos edifícios. Obviamente, o que vale para os componentes básicos do edifício se estende ao edifício como um todo: do momento em que adentro o território (físico e discursivo) da arquitetura, deixo de ver seus componentes como meras coisas construídas, senão, sempre, como fatos arquitetônicos. Com isso, inadvertida e inelutavelmente, deixo para trás o mundo físico e adentro o universo metafísico - a metafísica da presença arquitetônica.

A primeira incursão de Eduardo Coimbra pelo campo da metafísica da presença arquitetônica se deu quando, em setembro de 2013, colocou de pé (na Praça Tiradentes, Centro do Rio de Janeiro) duas esculturas de caráter eminentemente arquitetônico. Não me refiro apenas ao fato de que se assemelhavam às formas prismáticas da arquitetura 
funcionalista; ou que suas medidas correspondiam às de uma pequena edificação. Penso sobretudo em como suas unidades ou células espaciais (definidas por cubos metálicos parcialmente vazados) emulavam por regra espaços tipicamente arquitetônicos; como seus elementos construtivos básicos também se equiparavam aos componentes mais elementares da arquitetura: piso, parede e teto; como tudo aquilo parecia ter sido projetado e construído de molde a abrigar todas aquelas pessoas que, a qualquer hora do dia e da noite, sentissem vontade, ou mesmo necessidade, de adentrar aqueles espaços e ali deitar, descansar, dormir. Numa palavra, penso como aquelas duas esculturas se apresentavam deliberadamente como típicos fatos arquitetônicos. Que essas duas obras tenham dado lugar, ao longo de dois meses, a "ações tão díspares quanto transformar-se num cômodo ou servir como anteparo para brincadeiras" (como destacou Felipe Scovino) ${ }^{6}$, eis algo que não surpreende: tudo nelas parecia mesmo falar ao sujeito da arquitetura, o sujeito que não apenas busca abrigo na arquitetura mas que reconhece na arquitetura a representação mais arquetípica das noções complementares de abrigo e moradia.

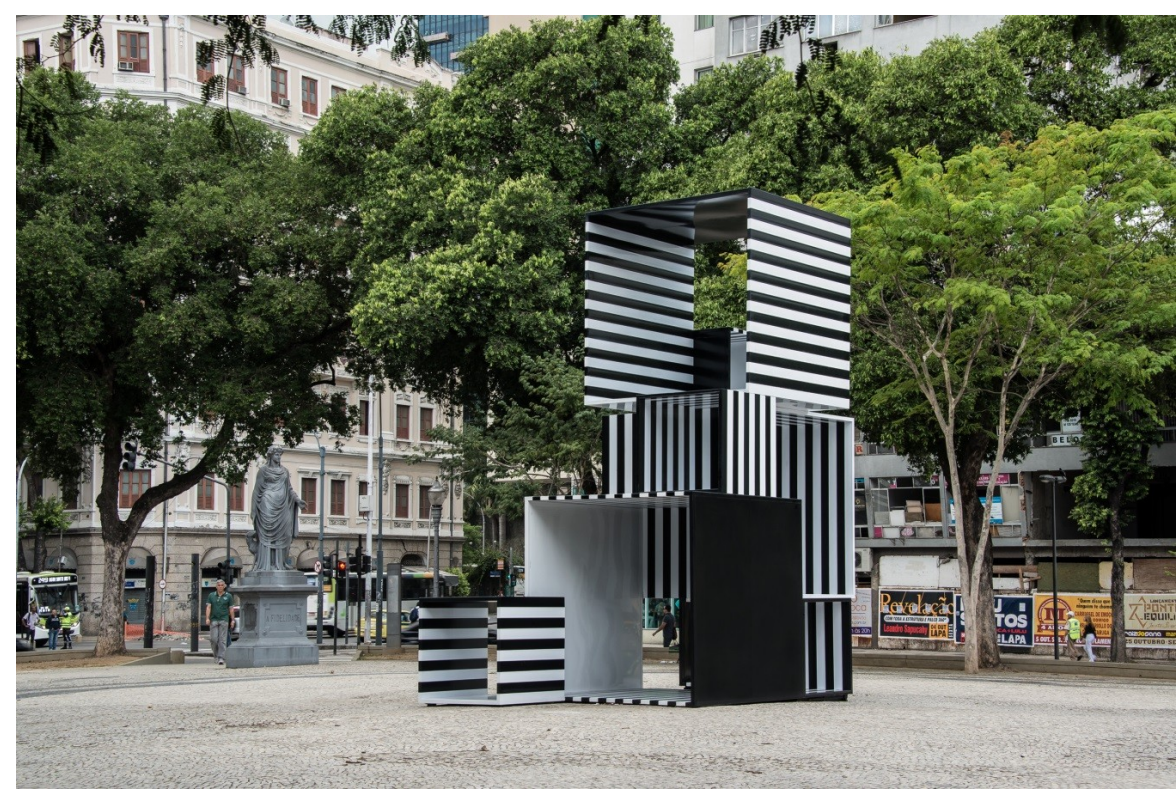

Escultura 1. Eduardo Coimbra, Praça Tiradentes, Rio de Janeiro, 2013 


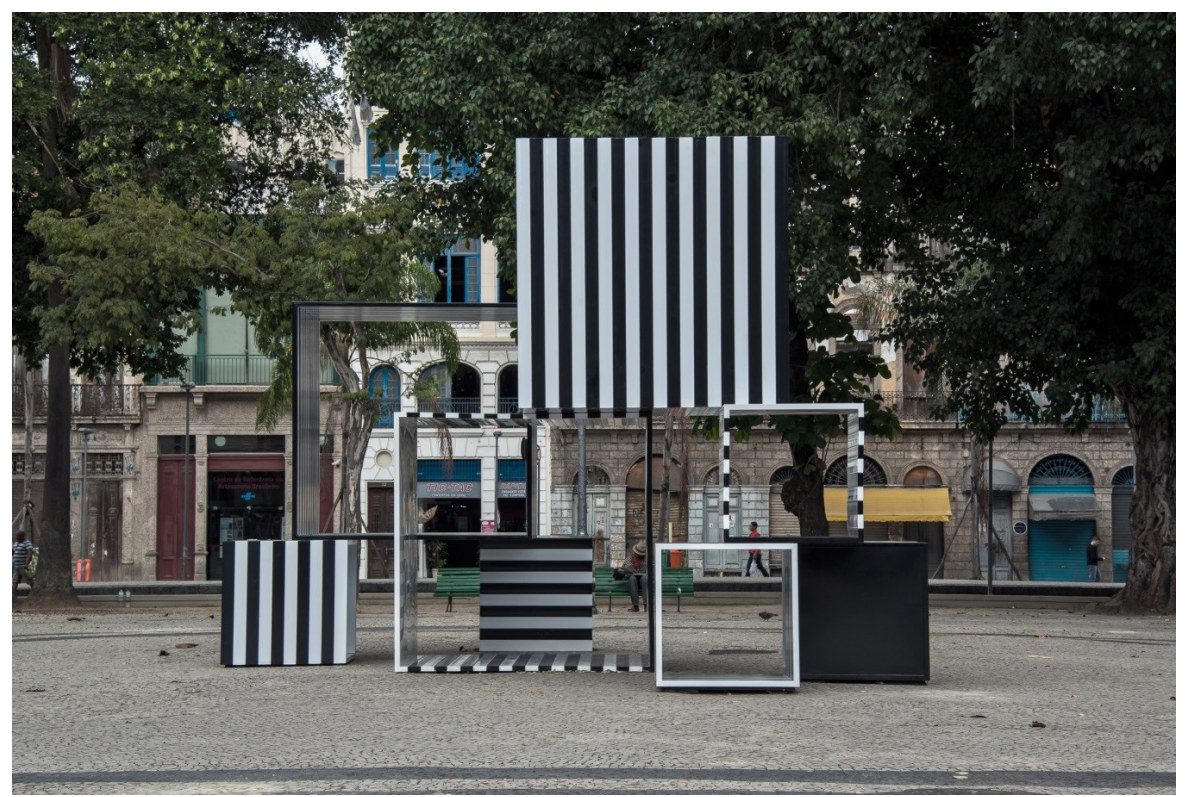

Escultura 2. Eduardo Coimbra, Praça Tiradentes, Rio de Janeiro, 2013

O que os Fatos arquitetônicos expostos recentemente na Galeria Nara Roesler (tanto quanto Uma escultura na sala construída na Casa de Cultura Laura Alvim $)^{7}$ deixam claro, no entanto, é que se Eduardo Coimbra optou por emular a arquitetura, ele fez isso com propósitos (convencionalmente falando) bem pouco arquitetônicos. Pois o que esses trabalhos fazem não é outra coisa senão desconstruir aquilo que aparentemente constroem: a arquitetura, a presença da arquitetura. Como fazem isso? Neutralizando um dos elementos mais essenciais do discurso arquitetônico - a noção de "escala humana", vale dizer, a ideia de que, por definição, todas as medidas de um edifício, e de todo e qualquer componente arquitetônico, devem sempre se referir ao corpo humano. É preciso destacar desde logo que tal noção não se restringe ao ideal de continuidade entre corpo humano e edifício; compreende também e sobretudo a ideia de que a arquitetura pode e deve operar como mediador por excelência entre corpo humano e paisagem. Dito de outro modo, o que a noção de escala humana pressupõe é a ideia de que, por meio da arquitetura, a paisagem - qualquer paisagem, por mais inóspita que ela seja - pode, ela também, se tornar abrigo e moradia. Subjacente à noção de escala humana está, portanto, um desejo de integração e continuidade entre três instâncias básicas do real: meu corpo, este ou aquele edifício, e esta paisagem (natural e sobretudo urbana). Dito de outro modo, subjacente à noção de escala humana está o desejo ancestral de transformar toda e qualquer noção de paisagem ("landscape", "townscape", "urbanscape") em humanscape. 


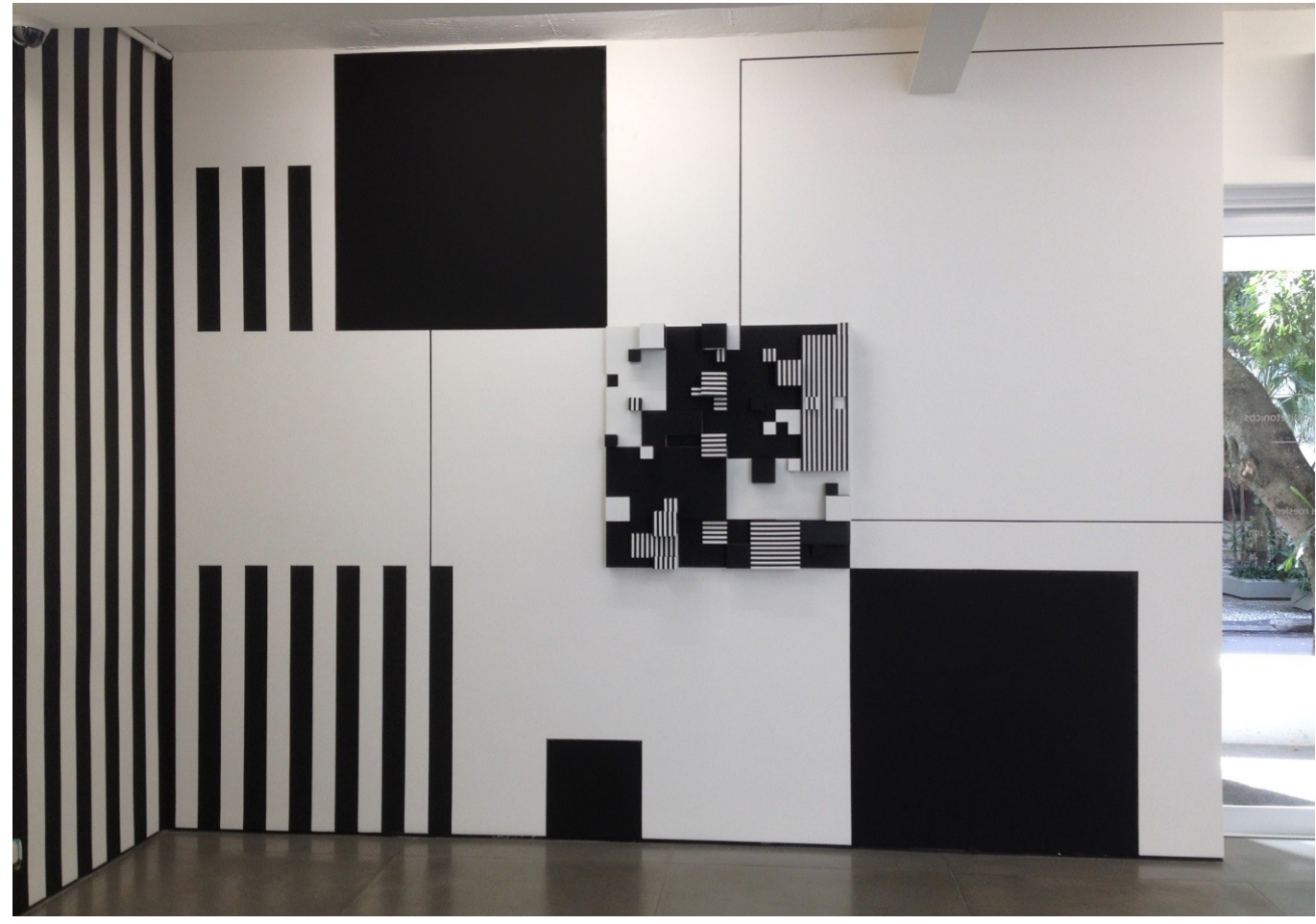

Fato arquitetônico. Eduardo Coimbra, Galeria Nara Roesler, Rio de Janeiro, 2015

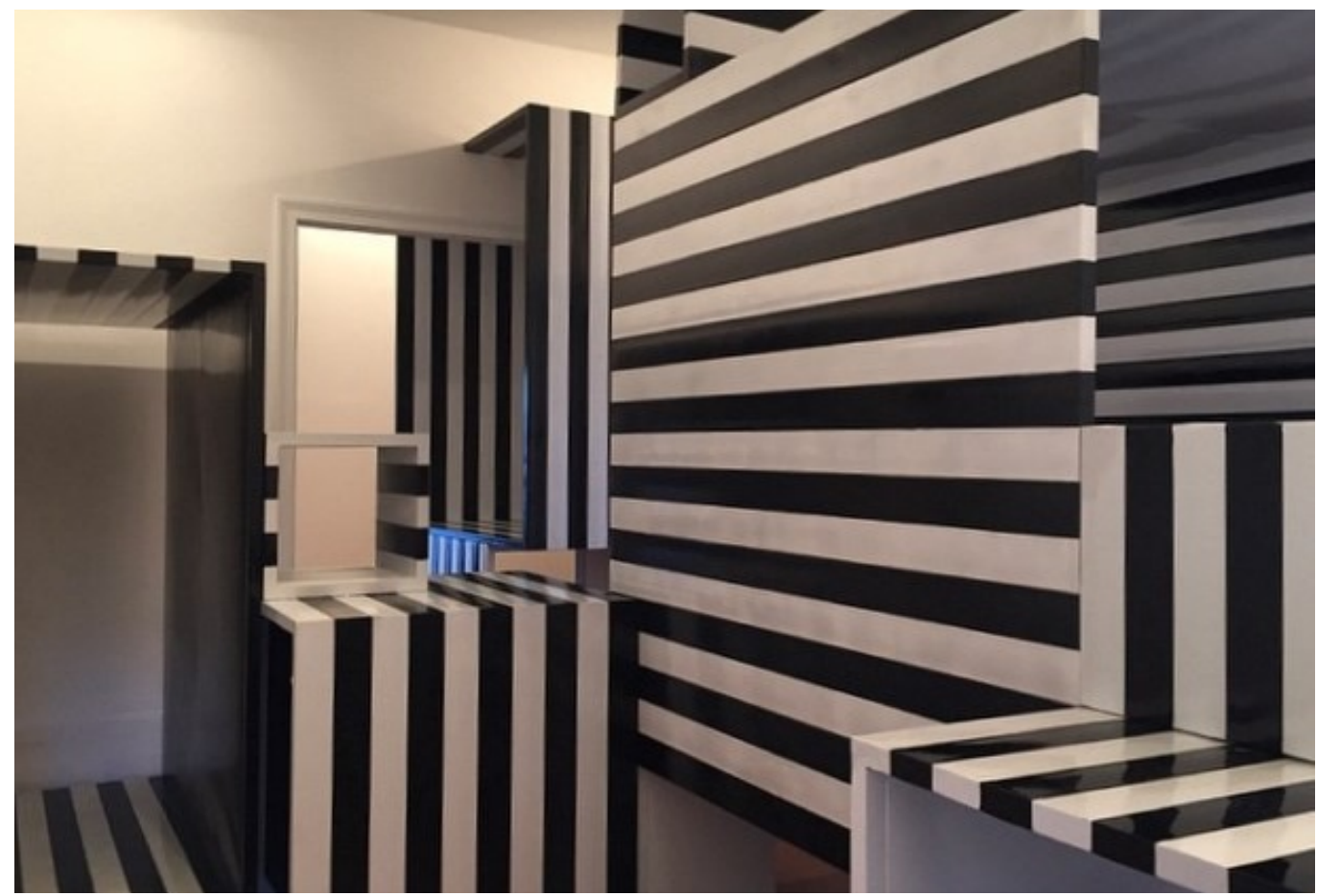

Uma escultura na sala, Eduardo Coimbra, Casa de Cultura Laura Alvim, Rio de Janeiro, 2015

É esse princípio antropomórfico e antropocêntrico básico do discurso (demasiadamente humano, diria Nietzsche) da arquitetura aquilo que os Fatos arquitetônicos de Eduardo Coimbra atacam. Pois o fato de emularem a linguagem da arquitetura não significa que 
se destinem exclusiva, ou mesmo prioritariamente, ao sujeito da arquitetura - quer dizer, o sujeito que vê na arquitetura um dispositivo essencial para a integração de seu corpo ao espaço real à sua volta, em suas múltiplas dimensões e instâncias.

Que os fatos arquitetônicos de Eduardo Coimbra se dirigem a uma outra subjetividade e a um outro corpo, é algo que fica claro quando se observa o modo como o artista os vem manipulando desde fins de 2013. Na Praça Tiradentes, eles apresentavam uma configuração tipicamente arquitetônica. Transportados para o espaço da galeria e do centro cultural, contudo, eles ganharam configurações, posições e dimensões totalmente novas; desenvolveram novas relações com o piso existente, com as paredes a seu redor, com o teto que os encobre; foram comprimidos, achatados, distorcidos, adulterados. E, até onde percebo, tudo isso ocorreu ao arrepio da noção de escala humana.

E é essa distorção radical, essa adulteração dos componentes (supostamente arquitetônicos) que constituíam as esculturas da Praça Tiradentes aquilo que impede que, na prática (foi essa em todo caso minha impressão), as novas configurações sejam percebidas, prioritária ou exclusivamente, como representações em escala reduzida da intervenção original. Ao contrário, o que sobrevém é a sensação de uma suspensão da lógica que comanda o sistema de representações arquitetônicas, baseado na noção de escala humana. Significativamente, assim como no caso de Horizontes para Vera (nos termos do discurso arquitetônico, uma construção em escala 1:1 de algo previamente representado em escala reduzida), aqui também entra em colapso o princípio segundo o qual a experiência arquitetônica "real" deve ficar sempre reservada ao âmbito do edifício ele mesmo, e não ao da maquete; que a condição suficiente para uma experiência autêntica do real é, portanto, a presença do corpo - mais especificamente, de um corpo humano naturalmente sensível às coisas que emulam sua escala; a todas aquelas coisas que foram construídas à sua imagem e semelhança, e que, por força da presença da arquitetura, se transformam em abrigo e moradia. 


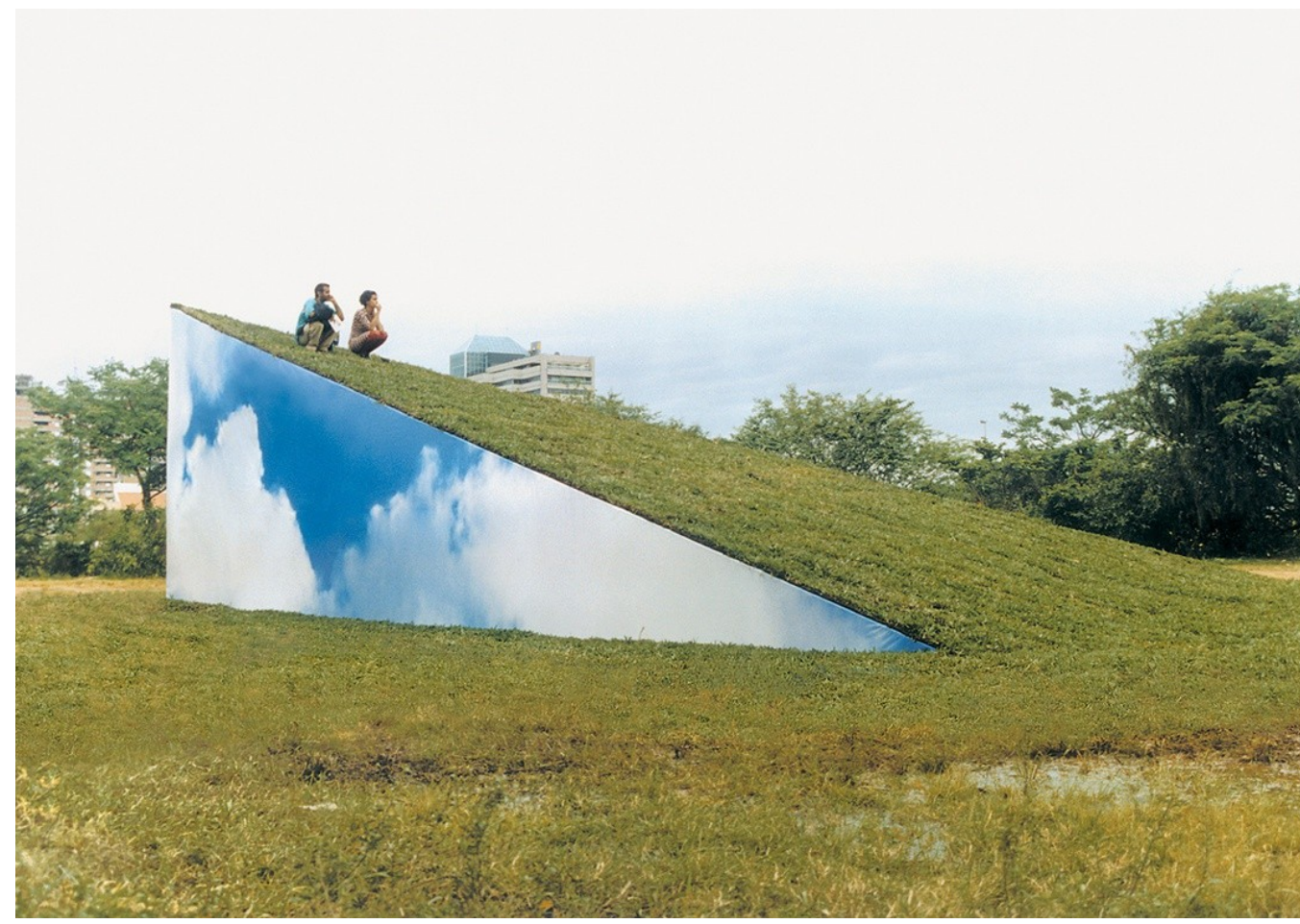

Horizontes para Vera. Eduardo Coimbra, 2001

O que os Fatos arquitetônicos de Eduardo Coimbra demonstram, nesse sentido, é a produtividade contemporânea (quer dizer, nem clássica/idealista nem moderna/mundana) de regimes estéticos nos quais a experiência da obra não pressupõe a presença do corpo sensível e demasiadamente humano de seus fruidores (como ocorre por exemplo no caso das elipses e trabalhos de terra de Richard Serra, mas também dos aconchegantes e sinestésicos penetráveis e ninhos de Hélio Oiticica), senão de um corpo dessensibilizado e desnaturalizado - o corpo que vertiginosamente percebe que é, ele também, representação, simulacro, ficção. 


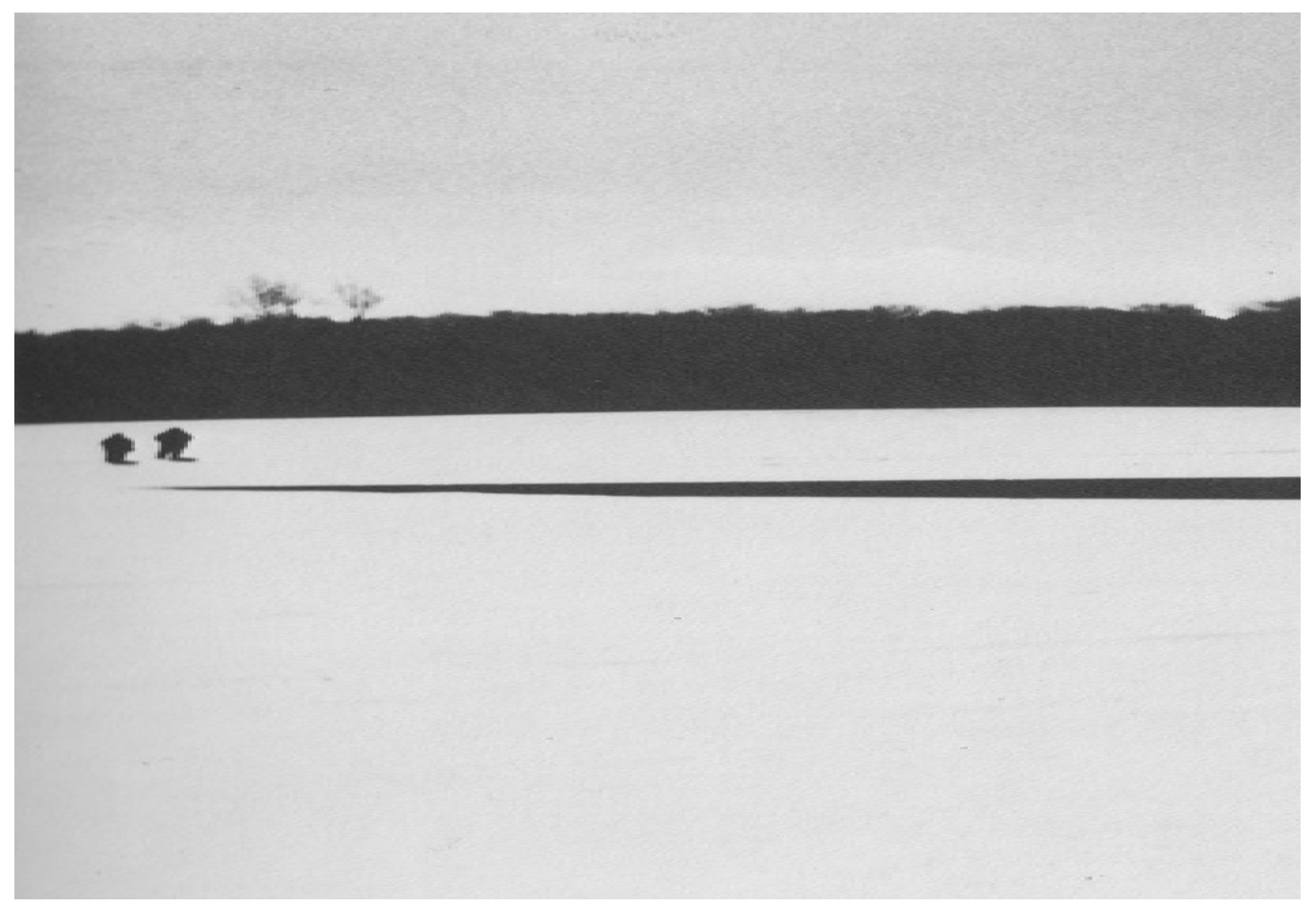

Shift. Richard Serra, 1971-72

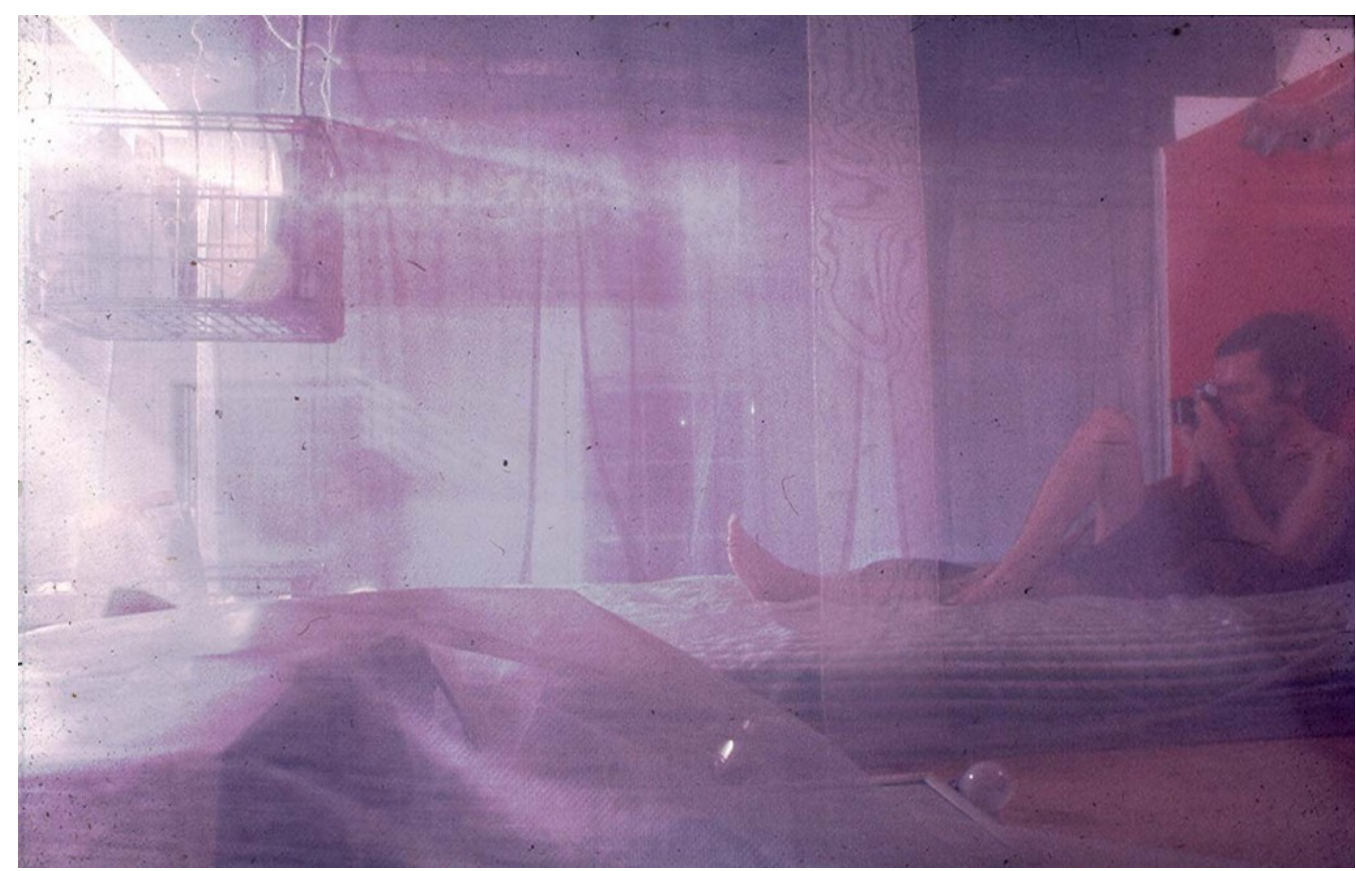

Ninho. Hélio Oiticica, 1969

Sendo assim, mais do que o espaço "real", o que as operações arquitetônicas de Eduardo Coimbra pretendem afrontar, adulterar e sobretudo desumanizar é o corpo "real". Pois se esses Fatos arquitetônicos são, como creio, simulacros de arquitetura, então os corpos que eles conjuram só podem ser, eles também, simulacros de corpos 
reais - personagens aptos a habitar algo que não é nem edifício, nem escultura, e nem maquete, nem sobretudo humanscape; algo que, como queria Eisenman, "a sabedoria popular chamaria de desastre". ${ }^{8}$

A extensão da divergência para com Eisenman (mas também com a extensa e duradoura linhagem Neoconcreta da arte brasileira, de extração eminentemente fenomenológica) fica clara. Pois se Coimbra quer desconstruir a metafísica da presença não é jamais para substituí-la por uma presença arquitetônica mais original e autêntica. Muito ao contrário, se ele desconstroi a presença metafísica dos fatos arquitetônicos é apenas para reconstruir outras ficções arquitetônicas. Um verdadeiro desastre.

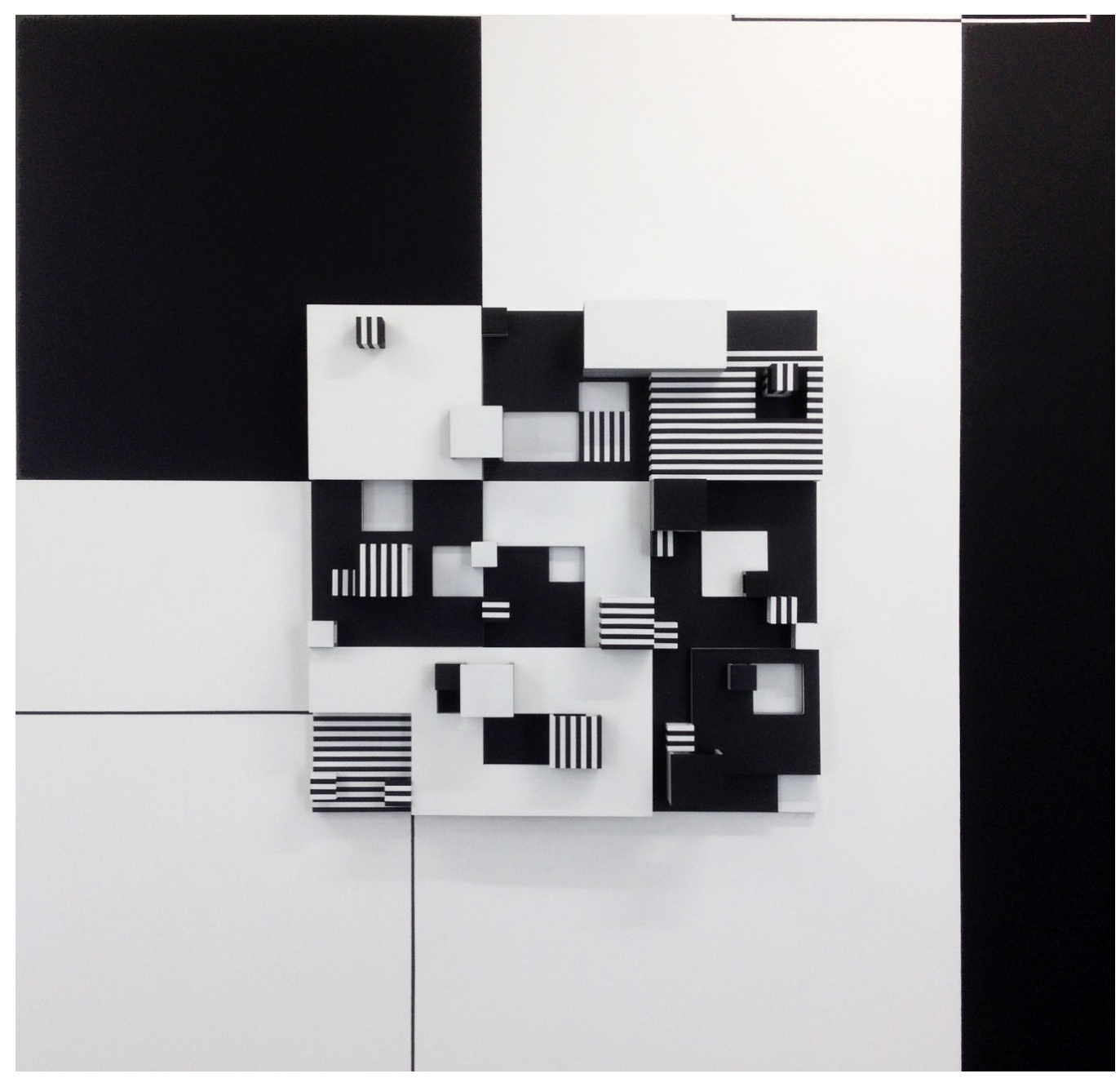

Fato arquitetônico. Eduardo Coimbra, Galeria Nara Roesler, Rio de Janeiro, 2015

* Otavio Leonidio é professor de arquitetura e urbanismo na PUC-RIO.

1 SERRA, R. "Interview" [Mar. 14, 1975]. In: SERRA, R. Writings Interviews. Chicago: The University of Chicago, 1994, p. 33. 
${ }^{2}$ EISENMAN, P. "A arquitetura e o problema da figura retórica” [1987]. In: NESBITT, K. (org.) Uma nova agenda para a arquitetura. São Paulo: Cosac Naify, 2013, p. 193.

${ }^{3}$ EISENMAN, P. "Peter Eisenman" [Entrevista]. In: ZAERA-POLO, A. Arquitetura em diálogo. São Paulo: Cosac Naify, 2015, p. 303.

${ }^{4}$ KRAUSS, R. "Sculpture in the Expanded Field". In: October, v. 8 (Spring, 1979), pp. 30-44.

${ }^{5}$ EISENMAN, P. "Peter Eisenman" [Entrevista]. Op. cit., p. 303.

${ }^{6}$ SCOVINO, F. "A escultura como abrigo". In: COIMBRA, E. 2 esculturas. Rio de Janeiro: Prefeitura da Cidade do Rio de Janeiro, 2013, pp. 20-28.

${ }^{7}$ COIMBRA, E. Fatos arquitetônicos. Galeria Nara Roesler, Rio de Janeiro, de 7/5 a 6/6 de 2015; Uma escultura na sala. Casa de Cultura Laura Alvim, de 30/4 a 28/06 de 2015.

${ }^{8}$ EISENMAN, P. "Peter Eisenman” [Entrevista]. Op. cit., p. 281.

${ }^{9}$ EISENMAN, P. “A arquitetura e o problema da figura retórica” [1987]. Op. cit., p. 194. 